\title{
ELECTRON BEAM WELDING OF LARGE-SIZE THICK-WALL STRUCTURES OF MAGNESIUM ALLOYS
}

\author{
V.M. NESTERENKOV and A.A. BONDAREV \\ E.O. Paton Electric Welding Institute, NASU \\ 11 Bozhenko Str., 03680, Kiev, Ukraine. E-mail: office@paton.kiev.ua
}

\begin{abstract}
In the nearest future in erection of space platforms and other large-size thick-wall structures the application of light magnesium alloys will be challenging. Therefore, the investigations on their updating and evaluation of a feasibility of producing the quality welded joints are urgent. In this work the results of experimental investigation of weldability of magnesium MA2 alloy of $100 \mathrm{~mm}$ thickness by electron beam and optimizing the technology of manufacture of large-size structures of this alloy are described. The variants of preparation and treatment of surface of edges to be welded and areas of base metal adjacent to it before welding are offered. From the results of penetration of metal across the whole thickness of the plate and metallographic investigations of peculiarities of weld formation, the optimal conditions of welding by accelerating voltage, beam current, focusing current, scanning parameters, deepening of focal spot and spatial butt position were established. The technical documentation was worked out and ready-metal assembly-welding stand was manufactured to perform assembly for EBW of billets of plates of $3000 \times 3000 \times 100 \mathrm{~mm}$ size. To prevent defects in external formation of joints, it was offered to use cover plates on the face side of a butt and backings on the side of a weld root, which are arranged along the whole length of a butt and manufactured of the same alloy. They should be fastened to the product to be welded on the tacks made by argon arc welding just after assembly on the stand. Considering the results of carried out investigations the plate structure of $3000 \times 3000 \times 100 \mathrm{~mm}$ size was manufactured of magnesium MA2 alloy using EBW. 5 Ref., 3 Tables, 6 Figures.
\end{abstract}

$\boldsymbol{K} \boldsymbol{e} \boldsymbol{y} \boldsymbol{w} \boldsymbol{o} \boldsymbol{r} \boldsymbol{s}:$ electron beam welding, magnesium alloys, large thicknesses, large-size structures, cathodes of welding guns, optimal welding parameters, coefficient of strength of joints, ultrasonic testing

At the present time among the variety of metal structural materials the light nonferrous metals, including also magnesium alloys, are widely applied. The main fields of their application are aircraft and rocket construction and also space vehicles building, where reduction in weight characteristics of the products has a great significance $[1,2]$.

The development of reliable methods for producing permanent welded joints will promote the wider application of magnesium alloys in manufacture of structures of large sizes. The solution of this problem concerns both the sphere of modernization of metallurgy of production of magnesium alloys of different alloying systems themselves and also investigations in the direction of development of technology of their welding using different methods. In the present work the results of investigations on evaluation of principal feasibility of application of magnesium alloy MA2 as applied to the production of large-size thickwall structures for the future space platforms are given.

(c) V.M. NESTERENKOV and A.A. BONDAREV, 2014
The first experiments on optimizing the technology of EBW of MA2 alloy showed the presence of great vapor-gas flow from weld pool. When that flow gets to the cathode spacing, it leads to increasing the pressure and occurrence of electric breakdowns in the gun. Therefore, it is necessary to increase either power of system for pumping out of cathode unit of the gun, which is not always possible to be realized at the operating machines, or working distance between the gun and the workpiece. In our experiments the working distance was set equal to $320 \mathrm{~mm}$.

Negative influence of vapor-gas flow affects also the condition of cathode surface. Aluminium and its oxides getting to the surface of lanthanum-boride cathodes form eutectics, which decrease the emission of electrons. The current beam is changed, which violates the geometry of penetrations. Especially this is observed in producing long welds, characteristic of the joints of billets of space platforms.

Under this reason the metal cathodes with the working temperature of $2800{ }^{\circ} \mathrm{C}$ find ever wider application during recent time, due to which the evaporation of metal particles from the surface of cathodes and prevention of cathodes metallization occur. The main difficulties in use of hightemperature metal cathodes are connected with high power of cathode heating and life of insu- 


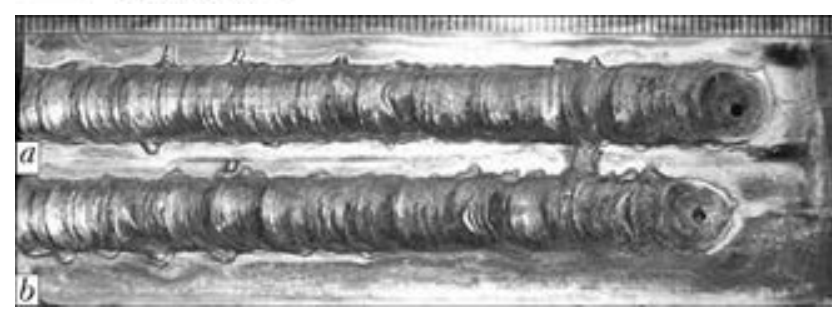

Figure 1. Formation of upper beads of welds in EBW of magnesium MA2 alloy (for $a$ and $b$ see the text)

lators and all the elements of cathode unit at high temperatures.

To decrease the power of heating the cathodes, a new design of fastening the tungsten electrode, manufactured using laser beam, was designed at the E.O. Paton Electric Welding Institute [3]. New design of tungsten cathodes of $3 \mathrm{~mm}$ diameter allows generating electron beam of $500 \mathrm{~mA}$ current at $70 \mathrm{~W}$ preheat power. Using tungsten cathodes of $4.2 \mathrm{~mm}$ diameter the beam current of $1000 \mathrm{~mA}$ is achieved at heating power of $100 \mathrm{~W}$. These cathodes, used by us in the investigations, showed high stability of formation of long welds at EBW of magnesium alloys of large thickness.

The stability of formation of welded joints on magnesium alloys is provided also by the stability of operation of the whole power complex of the machine. Even negligible non-uniformity in movement of alloy MA2 billets being welded has a negative influence on welds shape.

At instability of welding speed of more than $5 \%$, on the upper bead of welds the appearance of overlaps is clearly seen (Figure 1, $a$ ), and in the root the increasing in amplitude of variation in penetration depth can be observed. At instability of welding speed of less than $3 \%$ the nonuniformity of welds formation is reduced ( $\mathrm{Fi}-$ gure $1, b)$.

The necessary parameters of the system for moving the gun and the product were achieved

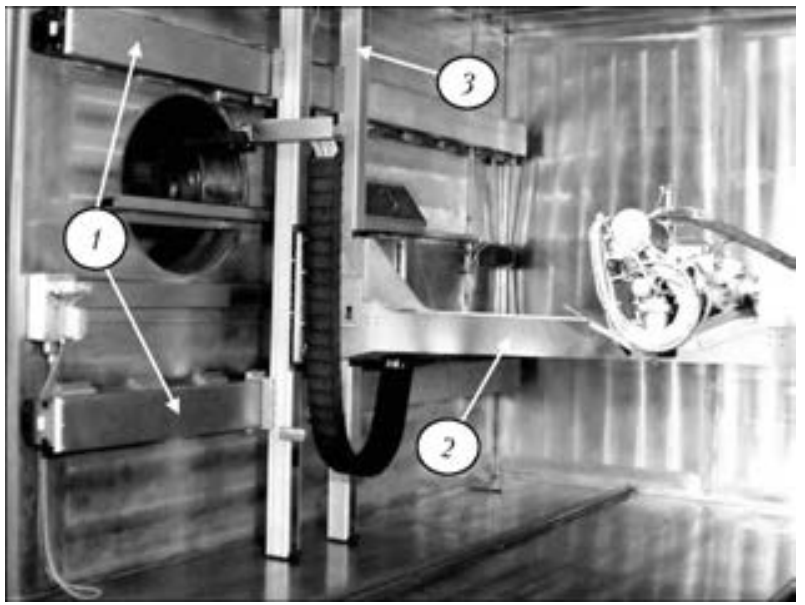

Figure 2. Mechanism of gun movement along the coordinates $X-X(1), Y-Y(2)$ and $Z-Z$ (3) using the machine for EBW equipped with linear modules MKK35 («Rexroth», Germany). Figure 2 shows the mechanism for movement of gun of machine UL 219, which was used in mastering the technology of MA2 alloy welding. It provided the sufficient accuracy of movement $(0.08 \mathrm{~mm})$ and met the requirements to instability of welding speed.

The mechanism has three levels of freedom along the axes $X-X, Y-Y$ and $Z-Z$. The movement of EB gun along the chamber in axis $X-X$ is performed by wheel-out of tables of linear modules MKK35-165 of $3800 \mathrm{~mm}$ length, which are equipped with a drive composed of two ball-andscrew gears with the pitch of $5 \mathrm{~mm}$, two gear belt transmissions with gear ratios $i=2$ and electric motor of $5 \mathrm{~N} \cdot \mathrm{m}$ torque.

At the tables of linear modules MKK35-165 two linear modules MKK25-110 of $2830 \mathrm{~mm}$ length are installed equipped with a drive, which is composed of one ball-and-screw gear with pitch of $5 \mathrm{~mm}$, one gear belt transmission with gear ratio $i=3.6$ and electric motor of $5 \mathrm{~N} \cdot \mathrm{m}$ torque. These modules allow the EB gun to move along the axis $Z-Z$.

In turn, a beam with linear modules MKK15-60 of $2200 \mathrm{~mm}$ length was mounted at the tables of linear modules MKK25-110 of $2830 \mathrm{~mm}$ length and equipped with a drive composed of one ball gear of $5 \mathrm{~mm}$ pitch, one gear belt transmission with gear ratio $i=3$ and electric motor with $0.83 \mathrm{~N} \cdot \mathrm{m}$ torque. These modules allow moving the gun along the axis $Y-Y$.

The speed of movement of EB gun along the axes $X-X, Y-Y$ and $Z-Z$ is preset in the limits of $6-120 \mathrm{~m} / \mathrm{h}(1.66-33.30 \mathrm{~mm} / \mathrm{s})$.

To provide control and accurate positioning, all the electric motors are equipped with sensors of angle movements. The signals from sensors are used to control EBW parameters using computer system on the base of high-precise CNC and PLC. Visual method of design of EBW programs is used [4]. Additionally to the applied traditional computational complex combining CNC and PLC in its composition, the machine UL 209 uses higher level of interface of operator for visual design of working programs and control of welding process, and also additional computer, which, independently of other processor units, solves the problems of butt identification according to the RASTR image of workpiece surface, obtained from the monitoring device, were introduced. Together with the main computer it provides performance of functions of automatic training, correcting and seam tracking. Visually designed program of welding during its launching for automatic performance, without participation of the 


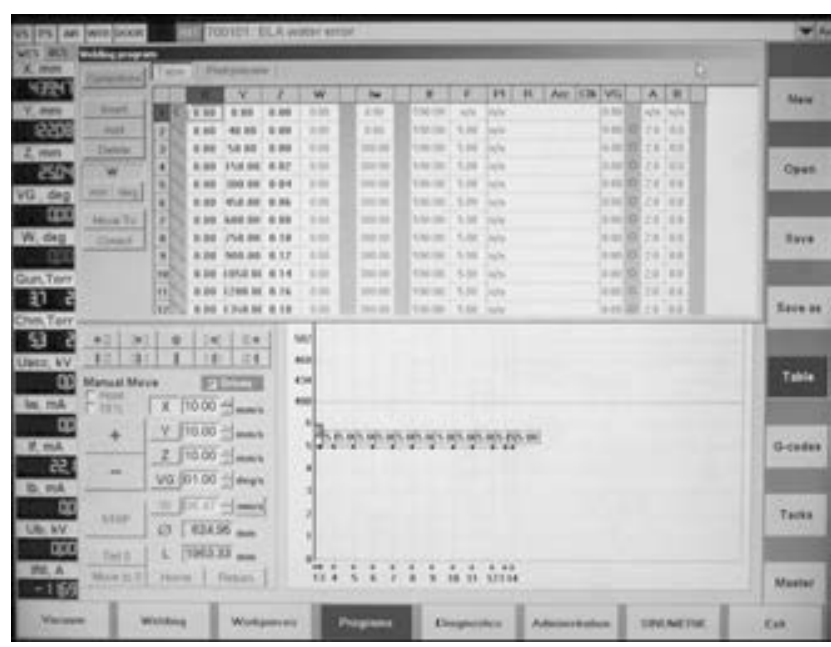

Figure 3. Example of visual programming of parameters of welding the butt joint of magnesium MA2 alloy

operator, is converted to the succession of $\mathrm{G}^{-}$ codes, executed by CNC. The example of such program, used for EBW of butts of magnesium MA2 alloy of $1500 \mathrm{~mm}$ length, is given in $\mathrm{Fi}$ gure 3 .

Mastering of technology of EBW of thick-wall magnesium alloy workpieces was performed in two stages. At the first one the experiments were carried out on optimizing welding mode parameters for stable formation of joints at complete absence of any defects of welds. On these butt joints the strength characteristics on specimens, cut out in different directions across the thickness of butts, were determined [5]. At the second stage the welding-assembly stands were designed and manufactured, their tests were made, and then welding was performed with their use and largesize structures for pilot production were manufactured.

Figure 4 shows the sketch of plate of space platform of magnesium MA2 alloy, which is welded of four billets of $1500 \times 1500 \mathrm{~mm}$ size and $105 \mathrm{~mm}$ thick. At the same sketch four holes of

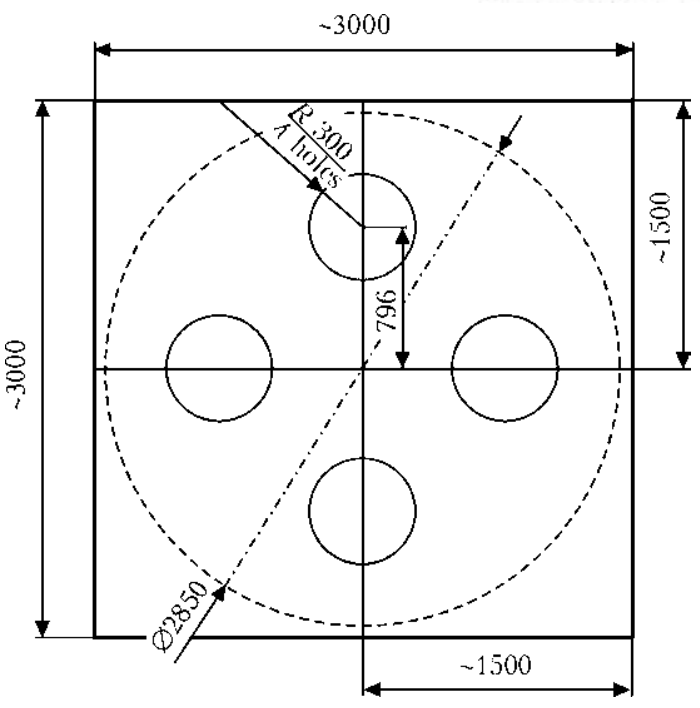

Figure 4. Sketch of design of the plate of magnesium MA2 alloy (chain line - diameter of plate cut out after welding)

$600 \mathrm{~mm}$ diameter are shown, which are cut out after welding.

In Tables 1 and 2 the chemical composition and mechanical properties of initial billets of 100 and $105 \mathrm{~mm}$ thickness are given, which were subjected to welding, and after optimization of parameters of welding conditions they were used for mechanical tests.

During evaluation of the influence of welding condition parameters on quality of welds formation the penetration was performed on base metal and then the macrosections were made, and presence or absence of defects in welds and HAZ were determined.

The stable quality of joints formation is achieved in producing horizontal welds in vertical plane using horizontal beam at the beam power of $16 \mathrm{~kW}$ and welding speed of $5 \mathrm{~mm} / \mathrm{s}$.

Figure 5, $a$ shows macrosection of cross section of produced welds in EBW using horizontal beam. All welded joints are characterized by the presence of undercuts on the side of beam entry

Table 1. Chemical composition of semi-products (plate) of different batches of magnesium MA2 alloy, wt.\%

\begin{tabular}{||c|c|c|c|c|c|c|c|c||}
\hline \hline № & $\begin{array}{c}\text { Plate } \\
\text { thickness, } \\
\mathrm{mm}\end{array}$ & $\mathrm{Al}$ & $\mathrm{Zn}$ & $\mathrm{Mn}$ & $\mathrm{Fe}$ & $\mathrm{Si}$ & $\mathrm{Cu}$ & $\mathrm{Ni}$ \\
\hline 1 & 105 & $3.35-3.57$ & $0.47-0.51$ & $0.34-0.42$ & $0.0048-0.0042$ & $0.0023-0.0420$ & $0.0010-0.0033$ & $0.0003-0.00052$ \\
\hline 2 & 100 & $3.5-3.8$ & $0.60-0.68$ & $0.1-0.2$ & $0.020-0.022$ & $0.14-0.18$ & 0 & 0 \\
\hline
\end{tabular}

Table 2. Mechanical properties of base metal of MA2 alloy semi-products at the tests of specimens cut out in different directions along the plate section

\begin{tabular}{||c|c|c|c|c|c|c|c|c|c|c||}
\hline \hline \multirow{2}{*}{$№$} & $\begin{array}{c}\text { Plate } \\
\text { thickness, } \\
\mathrm{mm}\end{array}$ & \multicolumn{4}{|c|}{$\sigma_{\mathrm{t}}, \mathrm{MPa}$} & \multicolumn{3}{|c|}{$\sigma_{0.2}, \mathrm{MPa}$} & \multicolumn{3}{c||}{$\delta, \%$} \\
\hline 1 & 105 & $255-260$ & $249-261$ & $246-269$ & $186-197$ & $190-192$ & $74.3-82.0$ & $14-16$ & $9.1-17.0$ & $11-13$ \\
\hline 2 & 100 & $237.2-250.8$ & $227.2-248.1$ & $270.9-277.5$ & $133.9-144.6$ & $131.1-139.8$ & $60.7-61.3$ & $9.4-21.0$ & $9.2-19.2$ & $18.2-18.3$ \\
\hline
\end{tabular}




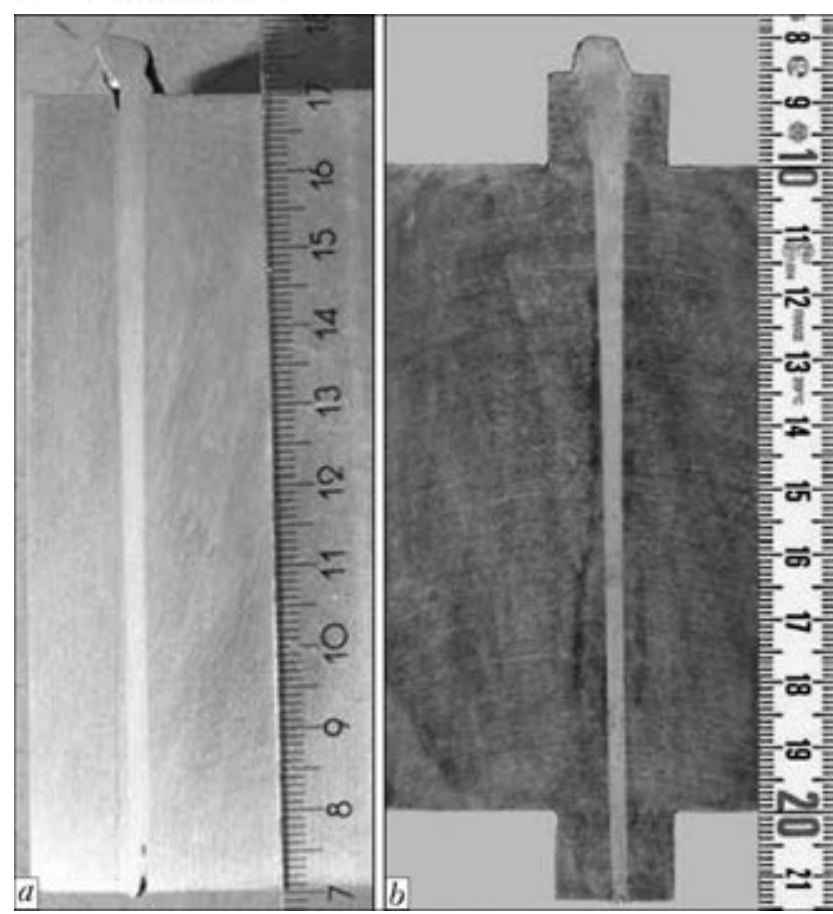

Figure 5. Transverse sections of welded joints of magnesium MA2 alloy (for $a$ and $b$ see the text)

and cover plates, which are installed at the top and in the butt root (Figure 5, b) and fastened before argon arc welding. The thickness of cover and backing plates was $15 \mathrm{~mm}$. Considering the increase in total penetration depth the welding current was also increased to $380 \mathrm{~mA}$. Welding speed, current of focusing lens $I_{\mathrm{f}}=590 \mathrm{~mA}$, accelerating voltage $U_{\text {acc }}=60 \mathrm{kV}$ and technological beam scanning around the circumference of $2 \mathrm{~mm}$ diameter remained unchanged.

In all the cases the surface of edges to be welded and also surfaces of plates adjacent to the butt were scraped to the depth of $0.1-0.2 \mathrm{~mm}$. In welding of billets of $1500 \times 1500 \times 100 \mathrm{~mm}$ size the butt tacks were made under condition: $I_{\mathrm{b}}=100 \mathrm{~mA}, I_{\mathrm{f}}=620 \mathrm{~mA}, v_{\mathrm{w}}=5 \mathrm{~mm} / \mathrm{s}$, oscillations of the beam around the circle of $2 \mathrm{~mm}$ diameter. At the butt of $1500 \mathrm{~mm}$ length 5 tacks of $120 \mathrm{~mm}$ length with the pitch between the tacks of $150 \mathrm{~mm}$ were performed. Before making tacks the butt was degassed by defocused electron

Table 3. Strength characteristics of welded joints of MA2 alloy

\begin{tabular}{||c|c|c|c|c|c||}
\hline \hline № & $\begin{array}{c}\text { Place of } \\
\text { specimens } \\
\text { cut-out }\end{array}$ & $\sigma_{\mathrm{t}}, \mathrm{MPa}$ & $\sigma_{0.2}, \mathrm{MPa}$ & $\delta, \%$ & $\begin{array}{c}\text { Strength } \\
\text { coeffi- } \\
\text { cient }\end{array}$ \\
\hline 1 & $\begin{array}{c}\text { Along the } \\
\text { rolling }\end{array}$ & $\frac{231.2-240.5}{235.2}$ & $\frac{132.9-141.0}{136.6}$ & 14.5 & 0.97 \\
\hline 2 & $\begin{array}{c}\text { Across the } \\
\text { rolling }\end{array}$ & $\frac{229.7-283.8}{232.0}$ & $\frac{131.6-138.9}{135.8}$ & 16.2 & 0.96 \\
\hline 3 & $\begin{array}{c}\text { Across the } \\
\text { thickness of } \\
\text { plate }\end{array}$ & $\frac{258.2-260.4}{259.3}$ & $\frac{72.4-81.7}{76.9}$ & 11.5 & 0.94 \\
\hline
\end{tabular}

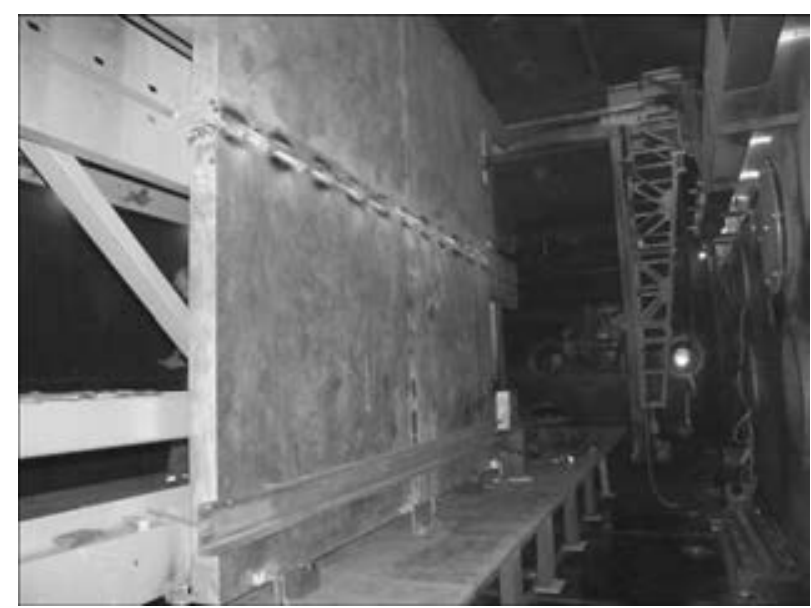

Figure 6. General view of platform of MA2 alloy before making the last weld of $3000 \mathrm{~mm}$ length

beam of small power. The tacks were made in the staggered order starting from the middle of butt length. Then, mechanical cleaning of their surface, installing and fixation of cover plate atop the butt and backing plate on the side of a root were performed. On the both sides of a butt the run-in and run-out tabs were mounted and fastened. In such a condition the butts of $1500 \mathrm{~mm}$ length were welded.

After completion of welding, the plates of $3000 \times 1500 \times 105 \mathrm{~mm}$ size were removed from welding stand, and cover plates were cut off from the face side of the plates, as well as root and run-in and run-out tabs at the beginning and end of welds were cut out using angular grinding machine.

EBW of the last butt of $3000 \mathrm{~mm}$ length was performed on the special assembly-welding stand. The tacks of a butt were fastened by electron beam on both sides with turnover of the workpiece beyond the vacuum chamber. The further cleaning of tacks and fastening of cover plates and run-out tabs were carried out according to the above-mentioned technology. The general view of the platform equipped and installed in the vacuum chamber is given in Figure 6 .

After welding, the table assembled according to the scheme like that is wheeled out from the chamber, welded product is transported using crane to the area of ultrasonic testing and measurements of residual deformation.

Simultaneously with the as-prepared and asassembled plate on the stand, the specimens-witnesses, necessary for the further manufacture of sections, intended for metallographic investigations, defining of distribution of hardness in the weld metal and HAZ and also for investigations of mechanical properties were loaded to the vacuum chamber. 
Round specimens for determination of ultimate rupture resistance were manufactured of different areas both across the thickness of a butt, as well as in different directions of rolling of plates at their metallurgical production. The test results of specimens are given in Table 3 . Having compared these data with the characteristics of the base metal, given in Table 2, one can make the conclusion that the coefficient of strength of joints in all the cases exceeds the value 0.9 , which had to be provided according to the technical assignment.

The quality control of welds after removing the plates from the assembly-welding stand was performed applying ultrasonic flaw detector UD2-70. The plate was arranged in this case on the lodgement in horizontal position in the way that the weld was in gravity position. The scanning was performed on the both sides of the weld. The ultrasonic testing of quality of butt welded joints with thickness of edges of $100 \mathrm{~mm}$ did not detect any defects along the total length of welds of $6000 \mathrm{~mm}$.

The evaluation of level of deformation of a plate according to the scheme of measurements of deflections showed that after producing of final weld the deformation of plate is varied within the limits of $\pm 1.5 \mathrm{~mm}$.

\section{Conclusions}

1. Principal feasibility of application of EBW in manufacture of thick-wall welded structures of magnesium alloys is shown.

2. Optimal parameters of conditions and basic technological requirements in EBW of billets of magnesium MA2 alloy with the thickness of edges of $100 \mathrm{~mm}$ were established.

3 . The technology of manufacture of large-size products of $3000 \times 3000 \times 100 \mathrm{~mm}$ of magnesium MA2 alloy was developed and passed pilot-industrial testing.

1. (1978) Magnesium alloys: Refer. Book. Vol. 1: Metals science of magnesium and its alloys; Vol. 2: Technology of production and properties of castings and deformed semi-products. Moscow: Metallurgiya.

2. Olshansky, N.A., Khokhlovsky, A.S. (1985) Properties of EB-welded joints of aluminium and magnesium alloys of large thickness. In: Actual problems of welding of nonferrous metals. Kiev: Naukova Dumka.

3. Nazarenko, O.K., Matvejchuk, V.A. (2012) Influence of violations of welding gun axial symmetry on focal spot position. The Paton Welding J., 7, 38-41.

4. Paton, B.E., Nazarenko, O.K., Nesterenkov, V.M. et al. (2004) Computer control of electron beam welding with multi-coordinate displacements of the gun and workpiece. Ibid., 5, 2-5.

5. Bondarev, A.A., Nesterenkov, V.M. (2013) Study of weldability of MA2 magnesium alloy by electron beam in vacuum. Kompres. Mashinostroenie, 2, 21-28.

Received 10.11.2013 